\title{
Nanoparticles in facade coatings: a survey of industrial experts on functional and environmental benefits and challenges
}

\author{
Ingrid Hincapié • Tina Künniger • \\ Roland Hischier • Dario Cervellati • \\ Bernd Nowack · Claudia Som
}

Received: 1 March 2015/Accepted: 17 June 2015/Published online: 5 July 2015

(C) Springer Science+Business Media Dordrecht 2015

\begin{abstract}
Integrating engineered nanoparticles (ENPs) into facade coatings is expected to offer considerable potential for improved or novel functionality, or even several functionalities at the same time (multifunctional materials). Little information is available about the tangible use of ENPs in facade coatings and the real improvements that their functionalities provide. In order to increase this information, we carried out a survey among selected coating manufacturers and ENP producers in Europe. We asked them about the improved functionalities enabled by ENPs, the quality of nanoenhanced facade coatings in comparison to conventional ones, and the handling of waste. The survey results indicated that the ENPs most frequently used in facade
\end{abstract}

Electronic supplementary material The online version of this article (doi:10.1007/s11051-015-3085-3) contains supplementary material, which is available to authorized users.

I. Hincapié · R. Hischier · B. Nowack · C. Som ( $\square)$ EMPA Swiss Federal Laboratories for Materials Science and Technology, Technology and Society Laboratory, Lerchenfeldstrasse 5, 9014 St. Gallen, Switzerland e-mail: claudia.som@empa.ch

T. Künniger

EMPA Swiss Federal Laboratories for Materials Science and Technology, Applied Wood Materials Laboratory, Überlandstrasse 129, 8600 Dübendorf, Switzerland

D. Cervellati

GFC Chimica S.r.1, Via Guglielmo Marconi 73, 44122 Ferrara, Italy coatings in Europe were silver, titanium dioxide, and silicon dioxide. The most frequently mentioned potential benefits were ultraviolet-protection, water and dirt repellency (easy to clean), and antimicrobial properties. Improving environmental performance through the use of nano-enhanced facade coatings did not appear to be a focus for innovation. The survey also revealed mixed results in the comparison between nano-enhanced and conventional facade coatings: $36 \%$ of respondents saw a notable improvement, $27 \%$ noted a gradual improvement of functionalities, and $37 \%$ detected no improvement over traditional materials. Some respondents mentioned a variety of tests that can be applied to investigate the quality of coating functionalities. These tests could be valuable in helping us to better understand the tangible improvements of nano-enhanced facade coating functionalities. Respondents were uncertain about how to properly handle the wastes resulting from nano-enhanced products.

Keywords Facade coatings · Paints - Engineered nanomaterials · Engineered nanoparticles innovation · Functionality $\cdot$ Environmental effects

\section{Introduction}

Facades are mainly made of mineral materials (e.g., concrete, bricks, or stone), wood, metal, and glass. A wide range of facade coatings is available, with different properties for each of the covering needs of 
the many substrates. These include aqueous polymer dispersions, alkyds, silicone-based coatings, silicate paints, lime paints, and aqueous distemper dispersions. Facade coatings are applied on exterior and interior surfaces (NanoHouse 2013), and they can be subject to the constant corrosive influences of weathering, traffic exhaust fumes, or microorganisms. Nanotechnology offers ways to counteract these unwanted effects, for example, via self-cleaning or scratch-resistant coatings (Som et al. 2011). Facade coatings also fulfill many other functionalities or requirements in addition to being decorative or esthetically pleasing. These include, but are not limited to, not settling during storage; short drying times; scratch and crack resistance; ease of maintenance; protecting the substrate from rain, splashing water, water vapor, UV radiation, and decay brought on my molds, mosses or microorganisms; air purification (mostly for interior uses); fire resistance and thermal protection; infrared reflectivity; and a long service life (Leydecker 2008; NanoHouse 2013).

It is widely expected that these functionalities can be improved by enhancing facade coatings with engineered nanoparticles (ENPs). Integrating ENPs into facade coatings also holds the potential for improving the product's environmental performance (Biswas and $\mathrm{Wu} 2005$ ) across its whole product life cycle, e.g., by replacing hazardous substances, reducing the generation of hazardous emissions and wastes, extending service life times, and reducing facade maintenance (Hischier et al. 2015). There are already several nano-enhanced facade coatings based on zinc oxide $(\mathrm{ZnO})$, titanium dioxide $\left(\mathrm{TiO}_{2}\right)$, silicon dioxide $\left(\mathrm{SiO}_{2}\right)$, aluminum oxide $\left(\mathrm{Al}_{2} \mathrm{O}_{3}\right)$, and silver $(\mathrm{Ag})$ ENPs on the market (Van Broekhuizen and Van Broekhuizen 2009). Projections estimate that by 2015 , nano-enabled coatings will represent $20 \%$ of the global market for coatings by value (i.e., USD 20 billion) (Lubick 2009). $\mathrm{TiO}_{2}$-ENPs have two attractive properties: (i) photocatalytic activity which degrades dirt and (ii) protection from UV radiation, thanks to their capacity for optical refraction. Adding $\mathrm{SiO}_{2}-$ ENPs to polymeric resins (i.e., binders) produces coatings with excellent abrasion resistance properties (Sangermano et al. 2005). Ag-ENPs are used as an antimicrobial agent (Hermann et al. 2009). Iron oxides and $\mathrm{ZnO}$-ENPs are used as UV radiation absorbers in transparent coating systems protecting substrates and organic matrix structures from photo-degradation.
Magnesium oxide $(\mathrm{MgO})$ ENPs have recently demonstrated their effectiveness as contact biocidal agents against bacteria (Baer et al. 2003). $\mathrm{Al}_{2} \mathrm{O}_{3}$-ENPs can be used to improve scratch resistance, and cerium dioxide $\left(\mathrm{CeO}_{2}\right)$ ENPs can be used for UV radiation protection on wood (NanoHouse 2013). However, many different factors must be considered if the expected properties of nano-enhanced coatings are to fulfill their potential. Kaiser et al. (2013), for instance, argued that it is currently not clear whether ENPs in paints will achieve all their promised benefits, just as other studies have raised concerns about the utility of $\mathrm{TiO}_{2-}$ ENPs (Marolt et al. 2011; Saha et al. 2011), $\mathrm{SiO}_{2^{-}}$ ENPs (Künniger et al. 2010; Zhou et al. 2002), and AgENPs (Künniger et al. 2014; Plaschkies et al. 2010).

Developments in the field of nanotechnology happen so quickly that it is challenging to provide a complete overview of which ENPs are currently being used in facade coatings or what future trends might be. There are currently several alternative international definitions of what nanomaterials and nanoparticles actually are (Jahnel et al. 2013; Saner and Stoklosa 2013), including some which are still in development. In some cases, it may thus be difficult to assess whether a given product really contains nanomaterials or not (Rauscher et al. 2014). As a result, shared information about nanomaterial use along the value chain of nano-enabled products is somewhat restricted. However, efforts to collect information about the nanomaterials used by industry have been carried out. The French Agency for Food, Environmental and Occupational Health and Safety (ANSES), for instance, has already published two substance declaration reports (ANSES 2013; ANSES 2014), and the German Federal Environment Agency, UBA, has produced a "Concept for a European Register of Products Containing Nanomaterials" (UBA 2012).

The expected increase in the use of ENPs in facade coatings raises certain concerns about their safety for human health and the environment. A further major source of uncertainty is the general lack of information on the potential release of ENPs from coatings, as only a few studies have looked at this question (Al-Kattan et al. 2013; Som et al. 2012). For instance, a study on the use of ENPs in the European construction industry (van Broekhuizen et al. 2011) stated that workplace measurements suggested that construction workers risked a modest occupational exposure to ENPs associated with the use of nano-products (of the total 
number of nano-products, coatings were identified as dominating the market, $68 \%$ ). The study revealed a significant lack of knowledge about the number of ENP-enhanced products on the market, the use of ENPs in the construction industry, and aspects of nano-safety. The handling and disposal of ENPenhanced products are also relevant in this context (Som et al. 2011). A recent report by the U.S. Environmental Protection Agency (EPA 2007) illustrated the need for a more appropriate treatment of all coating waste, whether from production or use.

In order to increase the available knowledge about the true uses of ENPs in facade coatings, the trends in innovation, and issues related to the benefits and risks of integrating ENPs into facade coatings, we carried out a survey among professionals from coating, paint, and ENP producers in Europe. Furthermore, we asked them about the tests used for the quality control of nano-enhanced facade coatings and how coating waste was handled.

\section{Methods}

We designed an online survey addressing the following seven topics: (i) the relevant functional benefits of ENPs; (ii) which ENPs can be used for which functions; (iii) the mass (wt $\%$ ) of ENPs used in facade coatings; (iv) the functional improvements brought to facade coatings by integrating ENPs; (v) the potential benefits for environmental performance; (vi) the treatment of waste from the production of ENPs and facade coatings; and (vii) additional information needs. These topics were covered with 17 questions (see all questions in the supplementary information, Section 1). We sent the questionnaire to paint companies and ENP producers in Europe using the online platform Surveymonkey. This study was intended to provide semi-quantitative information on how the coating industry perceives and handles the benefits and risks of nano-enhanced facade coatings.

We invited representatives from a total of 91 companies in Europe (known as either to use ENPs or to produce ENPs or products containing them) to fill in the survey. The companies were mainly selected by using contacts from two related projects (NanoHouse 2013; Piccino et al. 2012) and complemented by a few contacts found via an internet and literature research. Forty-five companies were small and medium-sized enterprises, SMEs (17 paint producers and 28 producers of ENPs), 22 were large paint producers, 21 were multinational chemical companies producing ENPs or additives containing ENPs, and four representatives were from paint industry associations. Of the 91 recipients, 20 answered and returned the questionnaire (i.e., $22 \%$ response rate). Among these 20 respondents, $40 \%$ were large paint producers (three of them were multinational key players in the paint market); $15 \%$ were SME paint producers; and $15 \%$ were paint industry associations. Large chemical companies and SMEs producing ENP represented 10 and $20 \%$ of the total respondents, respectively. We got answers from 10 different countries. With these answers, we consider to have a reliable coverage based on experience with online surveys (Hamilton 2009; Penwarden 2014).

\section{Results}

The survey questionnaire was mainly answered not only by large paint producers $(>50 \%)$ but also by SME paint producers $(>20 \%)$, for a detailed analysis see Section 2 of the supplementary information. Thus, our results are based on relevant stakeholders in the paint and coating sector.

\section{Relevant functional benefits of ENPs}

We asked representatives which properties they would like to improve or introduce into new facade coatings, the results are shown in Fig. 1. The most frequently mentioned desirable potential benefits and functionalities of nano-enhanced facade coatings were water and dirt repellency (easy to clean), $70 \%$ of respondents; UV-protection, $50 \%$; antimicrobial properties, $50 \%$; protection from mechanical wear (i.e., scratch resistance), $40 \%$; thermal insulation, $40 \%$; and material and energy savings, $40 \%$. Functionalities such as corrosion inhibition and color stability and protection of pigments were also mentioned.

Large companies and SMEs producing both paint and ENPs were interested improving water and dirt repellency. Functionalities such as UV-protection, antimicrobial, mechanical wear, thermal insulation, and material and energy savings were most reported not only by large and SME paint producers, but also by 
Fig. 1 Replies to "Which of the following properties would you like to improve or introduce into new facade coatings?"

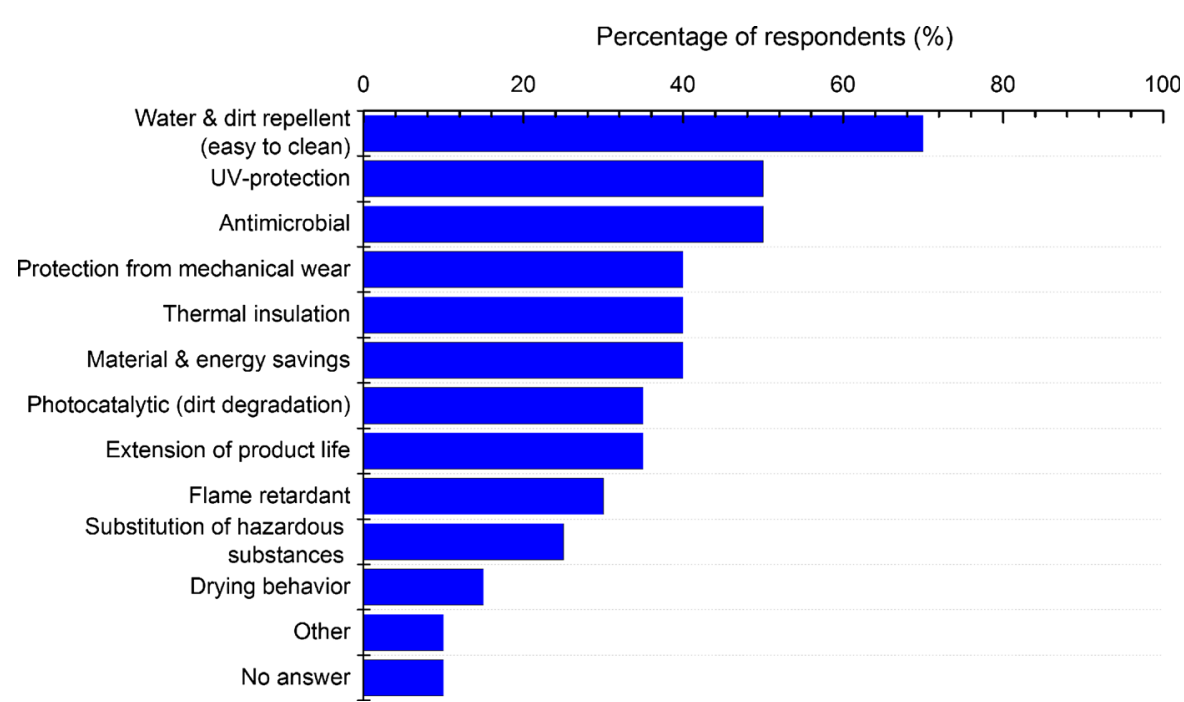

SME ENP producers. SME ENP producers reported special interest on improving flame retardant properties.

Which ENPs can be used for which functions

In order to identify which ENPs are used for which different functions, we asked representatives "Which facade coating functions can be improved with which nanomaterials?" The respondents mentioned that $\mathrm{TiO}_{2}, \mathrm{SiO}_{2}$, and Ag-ENPs were the most frequently used to improve different coating functionalities (Fig. 2). Although functionalized silanes are not ENPs, they were also mentioned, as they can be used to make facade coating surfaces hydrophobic (i.e., creating a pearl-off effect through self-assembled mono-layers).

While $\mathrm{TiO}_{2}$, and $\mathrm{SiO}_{2}-$ ENPs can be used to improve different properties (antimicrobial, water and dirt repellency, scratch resistance, colourability, UVprotection, photocatalytic activity, and flame retardancy) of the facade coating, Ag-ENPs are clearly only used to provide antimicrobial characteristics to the paints/coatings. Interestingly, some of the respondents (large and SME paint producers) were not familiar with the use of aluminum(hydr)oxides and nano clays $(24 \%)$, FeO-ENPs $(20 \%), \mathrm{SiO}_{2}$-ENPs (12\%), and $\mathrm{ZnO}-\mathrm{ENPs}(8 \%)$. Twenty four percent did not mention other properties. However, based on the results from Fig. 2 and a cross information analysis, only large paint producers were familiar with the use of all ENPs - provided in the survey-to improve functionalities of the facade coatings. Table 1 shows how the different companies answered what ENPs are used for what functionality.

Large and SME paint producers agreed in the use of at least one ENP depending of the functionality. All types of industry, especially large paint producers, reported that $\mathrm{TiO}_{2}$ and $\mathrm{SiO}_{2}$-ENPs can improve several properties of the facade coatings. Ag-salts (i.e, Ag-ions) and Ag-ENPs can be used for antimicrobial properties as well as aluminum(hydr)oxideENPs to improve flame retardancy. Knowing which ENPs are used in the facade coating industry, we also wanted to know what amounts of ENPs are used in the sector. We got answer only for $\mathrm{SiO}_{2}, \mathrm{TiO}_{2}$, and $\mathrm{Ag}$ ENPs. As stated by three of the multinational paint companies that participated in the survey, the estimated quantities of $\mathrm{SiO}_{2}, \mathrm{TiO}_{2}$, and $\mathrm{Ag}$-ENPs used (in metric tons per year, $t$ /year) in facade coatings on the European market were 100,50 , and $5 \mathrm{t} /$ year, respectively, plus 5 t/year for Ag-salts (i.e., Ag-ions).

Mass (wt\%) of ENPs used in facade coatings

In response to the question, "What amount of nanoparticles would you recommend to ensure facade coatings functionality?" company representatives recommended amounts of ENPs between 0.1 and $5 \mathrm{wt} \%$. For Ag-ENPs, less than $0.1 \mathrm{wt} \%$ was reported as necessary. However, more than $50 \%$ of the companies did not know what amount of ENPs should 


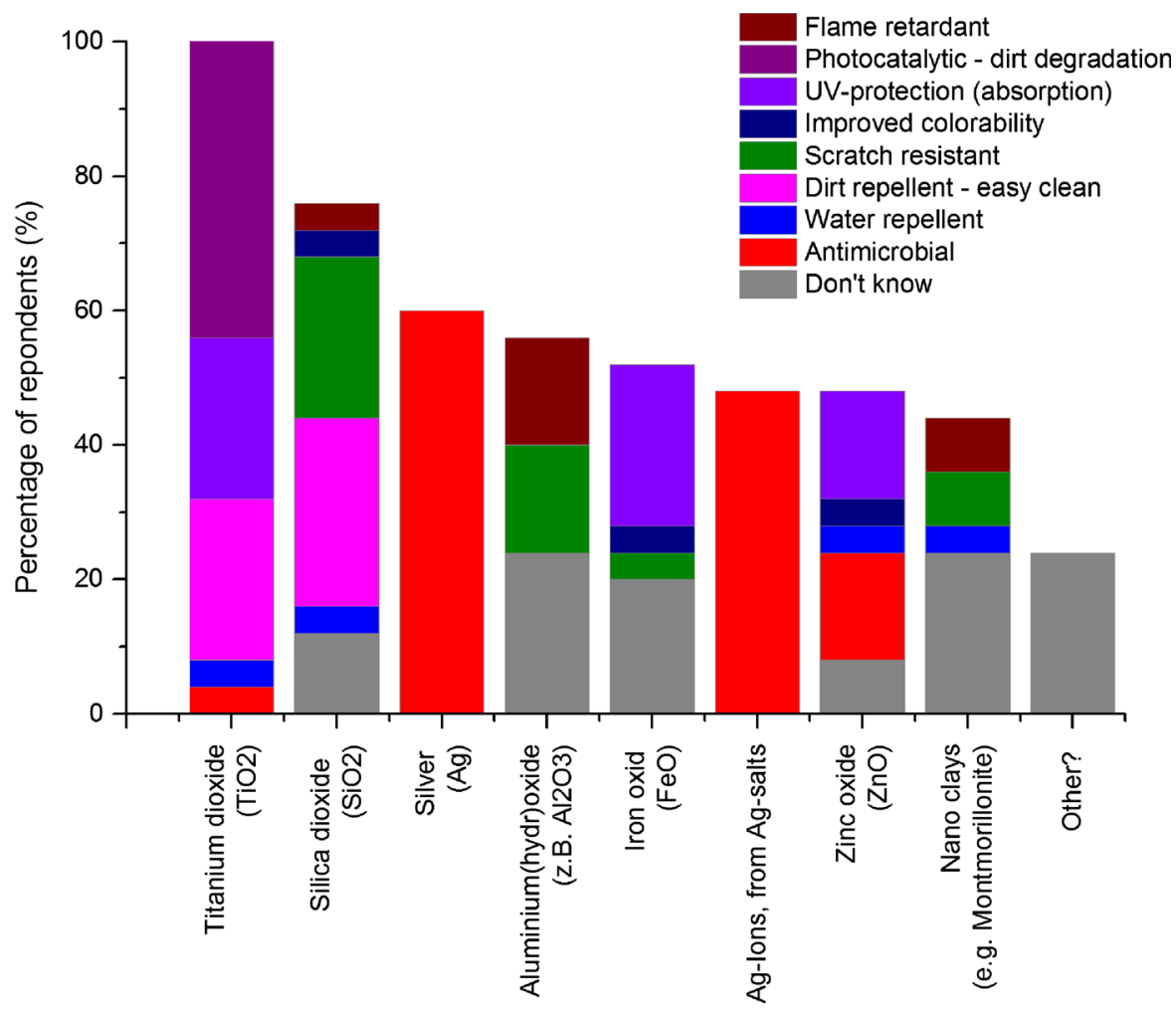

Fig. 2 The ENPs most mentioned in response to the question "Which facade coatings functions can be improved with which nanomaterials?"

Table 1 ENPs used for different functionalities according to the ENP and paint producers (more than one answer was possible)

\begin{tabular}{|c|c|c|c|c|}
\hline Functionality & Large paint producers & $\begin{array}{l}\text { SME paint } \\
\text { producers }^{\mathrm{a}}\end{array}$ & $\begin{array}{l}\text { Large ENP } \\
\text { producers }\end{array}$ & SME ENP producers \\
\hline Antimicrobial & Ag-ions, Ag and ZnO-ENPs & $\begin{array}{l}\text { Ag-ions, } \mathrm{Ag} \text { and } \\
\mathrm{ZnO} \text {-ENPs }\end{array}$ & $\begin{array}{l}\text { Ag-ions, Ag- } \\
\text { ENPs }\end{array}$ & $\begin{array}{l}\text { Ag-ions, } \mathrm{Ag} \text { and } \mathbf{T i O}_{2}- \\
\text { ENPs }\end{array}$ \\
\hline Water repellent & ZnO-ENPs, nano clay & - & - & $\mathrm{TiO}_{2}$ and $\mathbf{S i O}_{2}-\mathbf{E N P s}$ \\
\hline $\begin{array}{l}\text { Dirt repellent—easy } \\
\text { clean }\end{array}$ & $\mathrm{TiO}_{2}$ and $\mathrm{SiO}_{2}$-ENPs & $\begin{array}{l}\mathrm{TiO}_{2} \text { and } \\
\mathrm{SiO}_{2} \text {-ENPs }\end{array}$ & - & $\mathrm{TiO}_{2}$ and $\mathrm{SiO}_{2}-\mathrm{ENPs}$ \\
\hline Scratch resistant & $\begin{array}{c}\mathrm{TiO}_{2} \text { and } \mathrm{SiO}_{2} \text {-ENPs, nano clay, } \\
\text { Aluminum-(hydr)oxide-ENPs }\end{array}$ & $\begin{array}{l}\mathrm{SiO}_{2} \text {-ENPs, } \\
\text { nano clay }\end{array}$ & - & $\mathrm{SiO}_{2}$-ENPs \\
\hline $\begin{array}{l}\text { Improved } \\
\text { colourability }\end{array}$ & $\mathrm{SiO}_{2}$ and FeO-ENPs & ZnO-ENPs & - & - \\
\hline UV-protection & $\mathrm{TiO}_{2}, \mathrm{ZnO}$ and $\mathrm{FeO}$-ENPs & $\begin{array}{l}\mathrm{TiO}_{2} \text { and } \mathrm{FeO}- \\
\text { ENPs }\end{array}$ & $\mathrm{TiO}_{2}$-ENPs & - \\
\hline $\begin{array}{l}\text { Photocatalytic-dirt } \\
\text { degradation }\end{array}$ & $\mathrm{TiO}_{2}$-ENPs & $\mathrm{TiO}_{2}$-ENPs & - & $\mathrm{TiO}_{2}$-ENPs \\
\hline Flame retardant & $\begin{array}{l}\mathrm{SiO}_{2} \text {-ENPs, nano clay, aluminum- } \\
\text { (hydr)oxide-ENPs }\end{array}$ & $\begin{array}{l}\text { Aluminum- } \\
\text { (hydr)oxide- } \\
\text { ENPs }\end{array}$ & $\begin{array}{l}\text { Aluminum- } \\
\text { (hydr)oxide- } \\
\text { ENPs }\end{array}$ & $\begin{array}{l}\text { Nano clay, aluminum- } \\
\text { (hydr)oxide-ENPs }\end{array}$ \\
\hline
\end{tabular}

The ENPs in bold mean that they were the most mentioned by the companies (i.e., from $50 \%$ up to $100 \%$ of the answers)

- means no answer

${ }^{a}$ The paint associations are counted together with SME paint producers 
be in formulations (e.g., depending on the type of coating) or did not provide an answer.

Functional improvements brought to facade coatings by integrating ENPs

In order to evaluate the tangible functional improvements of nano-enhanced facade coatings in comparison to conventional ones (i.e., with no ENPs in the formulation), we asked the industries representatives: (1) What kind of standard quality tests does your company perform in order to analyze the quality of its nano-enhanced facade coatings? and (2) Do your company's nano-enhanced facade coatings show notable, gradual, or no functional improvements in comparison to conventional ones?

Concerning the first question, tests on weathering $(35 \%)$ and fungal resistance $(30 \%)$ were the most frequently performed, followed by water vapor permeability tests $(20 \%)$ (Table 2 ). Moreover, $10 \%$ of the respondents mentioned other tests, like scratch and abrasion resistance. However, $15 \%$ did not know which tests were used to prove the quality of their nano-enhanced facade coatings. Ten percent of the respondents declared that their company did not carry out any testing to prove the functionalities of its nanoenhanced facade coatings.

With regard to the standard tests in Table 2, and in answer to the question about whether nano-enhanced facade coatings displayed improved functionalities in comparison to conventional ones, $36 \%$ reported a notable improvement (answered by large paint producers) and $27 \%$ noted a gradual improvement (large paint producers; large and SME ENP producers). However, $37 \%$ reported no improvement in functionality (SME ENP producers, SME and large paint producers).

Although there are still no specific tests to evaluate the performance of nano-enhanced facade coatings, the use of the above-mentioned generic standards tests for conventional coatings may serve as a means to observe not only the quality of nano-enhanced coatings, but also their potential risks (e.g., release of ENPs). They could also be evaluated using weathering or release of substances tests, for instance.

Potential benefits for environmental performance

We asked industry representatives what the potential environmental benefits of integrating ENPs into facade coatings might be. The results showed clearly that the goal of integrating ENPs was to improve facade coating functionality and performance-the potential for improved environmental performance per se was not regarded as an important factor. However, the answers in Fig. 3 show that achieving an extended service life for the facade $(55 \%)$ was indeed important, as was substituting hazardous materials, i.e., chemical biocides (40\%). Saving energy through shorter drying cycles after the application of the facade coatings $(20 \%)$ was also considered a priority.

Table 2 Standard tests carried out by companies (more than one answer was possible)

\begin{tabular}{llr}
\hline Standard tests & & \\
\hline Adhesion & EN ISO 2409-EN 24624 (ISO 4624) & Percentage \\
Air permeability & DIN EN 12152 & 0 \\
Alkali resistance and resistance to water & ISO 2812/3-4 & 0 \\
Durability and color brilliance & VOB/C DIN 18363/2.4.1 & 15 \\
Fungal resistance & BS 3900:G6 & 30 \\
Liquid water permeability and crack bridging & DIN EN 1062/3,1062/7 & 15 \\
Release of substances & DIN 16105 & 5 \\
Resistance to impact & DIN EN 14019 & 5 \\
Resistance to wind load & DIN EN 13116 & 10 \\
Spreading rate & ISO 6504/1-3, NF T 30 073 & 5 \\
Thermal insulation performance & EN ISO 10077/2 & 10 \\
Water-tightness & DIN EN 12154 & 0 \\
Water vapor permeability & ISO 7783/2 & 20 \\
Weathering & ISO 4628/2-6, ISO 2813, ISO 11507, EN 927-6 \\
\hline
\end{tabular}




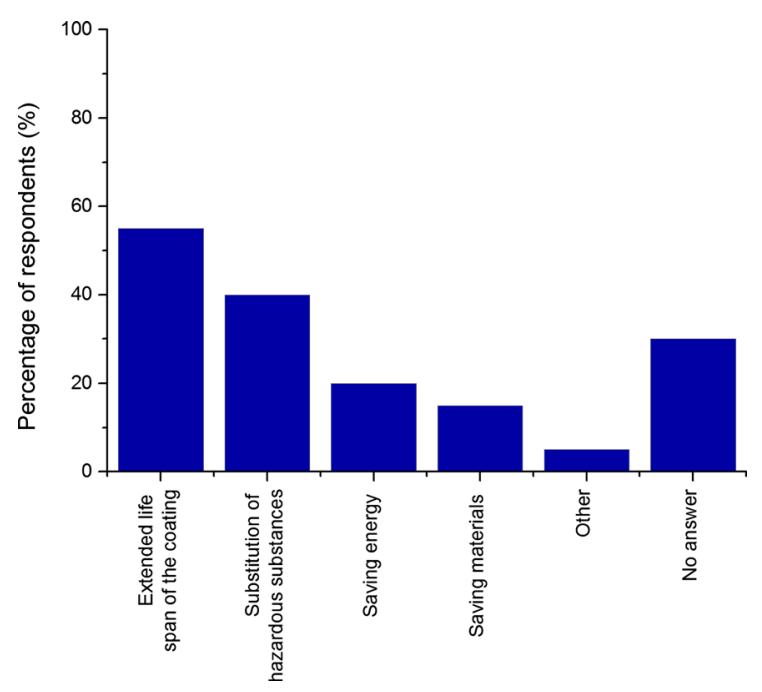

Fig. 3 Answers to the question: What are the potential environmental benefits of integrating nanomaterials into facade coatings?

All types of companies were interested in the potential environmental benefits given by the questionnaire (extending life span of the facade coating, substitution of hazardous substances, saving energy and materials). Large paint producers were especially interested in saving materials (in the formulation of the paint), and in extending the life span. SME paint producers were mainly interested in saving energy by shortening the dry cycles after the application of the facade coating. However, extending the service life was a major priority. In order to know how long the effectiveness of nano-enhanced facade coating functionalities will be guaranteed after the first use, we asked them "How long will the effectiveness of nanofacade coatings properties be guaranteed after the first use?" Twenty percent of the companies answered that the effectiveness of coating properties was supposed to be up to 10 years. Only $5 \%$ of respondents answered that ENP effectiveness could be guaranteed for more than 10 years; $35 \%$ did not answer the question; $30 \%$ did not know how long the enhanced properties of the facade coating might remain. However, $10 \%$ of respondents commented that guaranteeing more than 10 years of nano-enhanced functionality was difficult - the ENPs may indeed still be functional, but that functionality would be subject to the condition of the facade coating into which it was integrated.
Another way to approach the quality and/or the environmental performance of the product was to know if the companies already had any experience with quality certifications. Thirty percent of respondents already had Quality Management (ISO 9000), environment management (ISO 14000), or occupational health (OHSAS 18000) certification in different departments of their company, mainly in manufacturing, management, and product quality. Two companies also had energy management (ISO 50001) certification, general requirements for the competence to carry out tests and/ or calibrations (ISO 17025), or Management System Certification (DEKRA). Although there was an awareness of quality and environmental practices, $20 \%$ of respondents did not know which certifications their companies had, $5 \%$ had no certified processes for their nano-products, and $45 \%$ provided no information. However, when asked about what their companies did to evaluate and minimize health and environmental risks, respondents expressed great interest in evaluating and minimizing health and environmental risks. Fifty percent of participants thought it is relevant to study specialized journals, $40 \%$ thought it is important to participate in dialog events or research projects, $35 \%$ sought expert opinions, and $10 \%$ valued toxicological testing. Also mentioned were migration studies (i.e., release studies), measurements of particle numbers (i.e., particle size, distribution, and quantity), and preventive actions for employees and the safe handling of ENPs.

Treatment of waste from the production of ENPs and facade coatings

We asked representatives how their companies treated nanomaterial waste, and how they recommended that the waste from nano-enhanced facade coatings be treated. However, there seemed to be a general lack of information about the treatment of waste from the production of ENPs (54\% of the answers) or the production of nano-enhanced facade coatings (46\% of the answers) (Fig. 4). With regard to the production of ENPs and ENP-additives, $8 \%$ of participants indicated that these residues were incinerated; $15 \%$ answered that they were treated as hazardous waste. Twenty-three percent answered that other treatment methods were applied, according to the composition of waste, but they did not mention what these other methods were. 
Fig. 4 Disposal of ENP waste and nano-enhanced facade coatings waste. Question: How do you treat nanomaterial waste, and how do you recommend the waste from nano-enhanced facade coatings be treated?

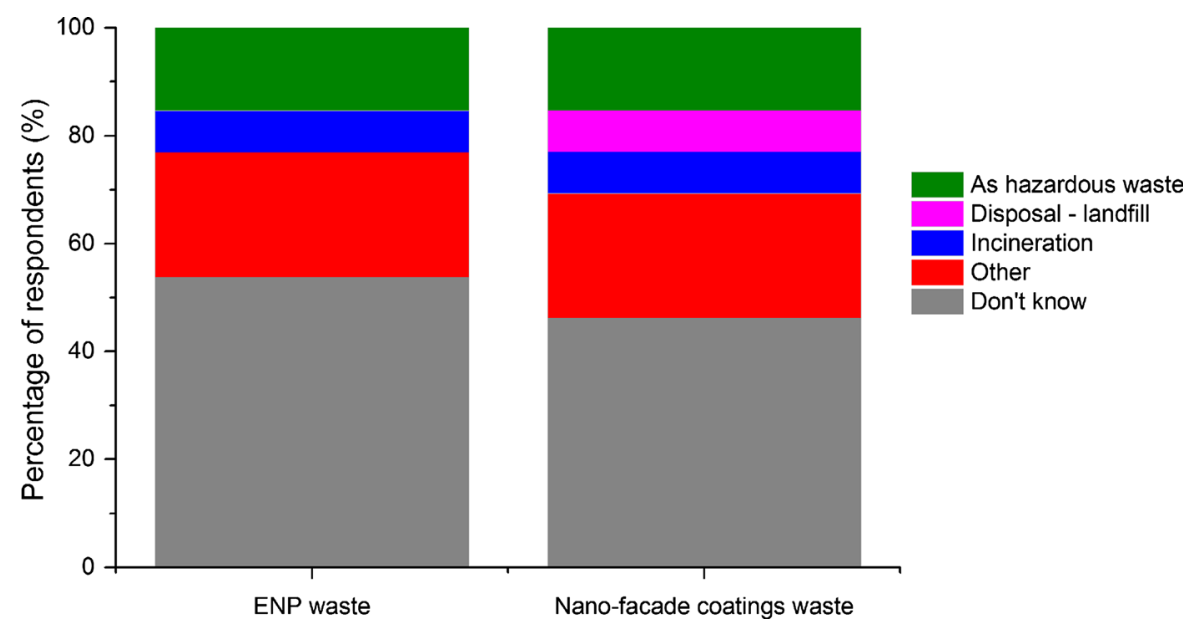

With regard to waste from the production of nanoenhanced coatings, $8 \%$ of participants declared that their company (SME paint producers) incinerated these residues, $8 \%$ said they went to landfill (SME ENP producers), $15 \%$ treated them as hazardous waste (SME ENP and large paint producers), and $23 \%$ of the participants (SME ENP and paint large producers) treated their residues using other methods based on safety data sheets and guidelines from the German Chemical Industry Association (VCI). According to the European waste catalog and hazardous waste list (European Environmental Protection Agency, EPA (2002)), paint waste is classified as hazardous (i.e., waste from the manufacture, formulation, supply, and use of coatings including paints, varnishes, and vitreous enamels, as well as sealants and printing inks). Companies need up-to-date information about how to properly dispose of their residues throughout their products' entire life cycles.

\section{Additional information needs}

In answer to the question, "In which topics would you most likely need more information?" respondents mentioned several different ones. For instance, $40 \%$ of companies were interested in the potential for ENPs to provide new or improved features to coatings, $35 \%$ were interested in the latest developments in the national regulation of nano-products, $35 \%$ in their international regulation, $30 \%$ in the state of knowledge on the risks of ENPs on health and the environment, $30 \%$ in "best practices," and $20 \%$ in the safe use of ENPs.

\section{Discussion}

Our results constitute an up-to-date source of information about nano-enhanced facade coatings and industry expectations about improvements to their functionality and environmental performance. The survey illustrated that there was little information available about the types and amounts of ENPs used in the coating industry and about the underlying mechanisms of how the integration of ENPs improves the functionality of the facade coatings. However, this survey did clarify some trends regarding these issues, as well as which functional benefits could be generated by which types of ENPs.

Our survey revealed that SMEs were especially in need of information; a survey carried out by van Broekhuizen et al. (2011) showed similar results. However, larger companies were able to provide data on the amounts of ENPs they used in facade coatings on the European market and seemed to have specific information about the ENPs they use. The survey indicated that $\mathrm{TiO}_{2}, \mathrm{SiO}_{2}$, and $\mathrm{Ag}$ were the most used ENPs in facade coatings. Companies stated that ENPs were not always integrated directly into the coating formulation, but rather appeared in the form of intermediate products, such as additives or resins.

The majority of respondents expected the integration of ENPs into facade coatings to lead to improved or new functionalities across several stages of their life cycles, but mainly during the material's use phase (i.e., "easy to clean" properties, UV-protection, antimicrobial properties, and scratch resistance). However, respondents reported mixed results concerning the 
performance of ENP-enhanced facade coatings versus traditional ones: $36 \%$ saw a noticeable improvement, $27 \%$ noted gradually improved functionalities, while $37 \%$ detected no improvement compared to traditional materials. This result coincides with the few studies available about this topic, for instance (Künniger et al. 2014; Marolt et al. 2011; Zhou et al. 2002), where the functionality of coatings containing nano- $\mathrm{TiO}_{2}$ (photocatalytic property), nano-SiO (scratch resistance and elasticity), and nano-Ag (antimicrobial efficacy and Ag-ENP release) was evaluated. This reflects the significant challenges of achieving the desired functionalities in a facade coating simply from the knowledge of the properties of a particular ENP. Thus, the companies want more information about the improved functionality and benefits ENPs will bring to coatings under real-world conditions.

There is almost no information available about the underlying mechanisms of the interaction between ENPs and the matrix materials of the products which they enhance, including functionality. Integrating ENPs into a coating formulation does not automatically mean that the product will be of better quality or that the ENPs will retain their original form and functionality in the end-product (e.g., agglomerated ENPs or stable networks of ENPs). Thus, achieving different functional improvements in coatings by integrating ENPs is not always certain and this is the challenge facing both ENP manufacturers and facade coating producers. Firstly, it is important to understand the chemistry of the coating itself (e.g., formulation methodologies for selecting the ingredients in complex mixtures of $>20$ substances in order to achieve key consumer attributes) (BCF 2013); secondly, it is important to understand in what form (single, free particles, agglomerates, or chemically bound networks) and how (chemically, mechanically, absorption) ENPs are bound into the product matrix (Som et al. 2014). Processes using hydrothermal synthesis, for instance, can produce nanoparticles and pre-stabilized particles, thus avoiding agglomeration; however, extremely careful formulation is the key to generating maximum benefits (BCF 2013).

It seems that qualitative improvements of nanoenhanced facade coatings could be explored using the standard tests for conventional coatings. Standard tests exist to investigate the quality of facade coatings, such as durability and color brilliance (VOB/C DIN
18363/2.4.1), resistance to impact (DIN EN 14019), weathering (ISO 4628/2-6, ISO 2813, ISO 11507, EN 927-6), or release of substances (DIN 16105) (Table 2). However, the development of specific quality tests for ENP-enabled coatings would be a valuable step.

Some of the current tests may indicate how stable the integration of ENPs is in the nano-enhanced coating and thus indicate whether any exposure to released ENPs can be expected. To date, there have only been a few studies on the release of ENPs from facade coatings. However, they showed that the release of $\mathrm{TiO}_{2}$ and $\mathrm{SiO}_{2}$ from outdoor paints seemed to be low, and there is probably not a major mass flow of nano- $\mathrm{TiO}_{2}$ and nano- $\mathrm{SiO}_{2}$ into the environment (AlKattan et al. 2013, 2014; Kaegi et al. 2008; Zuin et al. 2014). Nano-Ag, on the other hand, exhibited quite a substantial release of particles during outdoor weathering tests on a model house (Kaegi et al. 2010).

With regard to the potential for improving environmental performance by including ENPs into facade coatings, $20 \%$ of respondents expected that it was possible to save materials and energy during production, $40 \%$ thought hazardous substances could be substituted from the final product, and $55 \%$ hoped ENPs would reduce facade maintenance and extend their serviceable life time. However, due to some respondents not answering at all (30\%), and the results mentioned before, the survey indicated that using the potential of ENPs to improve environmental performance is not the current focus of innovation, i.e., it seems that achieving improvements in coating functionality are the priority.

There is little literature available about the real improvements in environmental performance brought about by nano-enhanced facade coatings. Hischier et al. (2015), for instance, addressed the potential environmental, health, and safety (EHS) impacts of coatings containing ENPs by carrying out a life cycle assessment (LCA) of the whole product life cycle and the potential releases of ENPs during it. The main goal of this study was to elucidate whether nano-enhanced facade coatings result in a better environmental performance than conventional facade coatings without ENPs. Facade coatings containing nano- $\mathrm{TiO}_{2}$, nano-Ag, and nano- $\mathrm{SiO}_{2}$ were examined, and each was compared to facade coatings with the same characteristics, but without ENPs. Results showed that the potential for environmental benefits depends very 
much on the actual composition and functionality of the paint itself, and the addition of various ENPs cannot be generalized. The following factors were determinant for an improved environmental performance: (i) the ENP added has to substitute an (active) ingredient in the paint's initial composition and not simply be an additional ingredient; (ii) the new composition has to extend the paint's useful lifetime long enough so that the total consumption of paint during a building's life cycle can be reduced; and (iii) the releases of ENPs must be reduced to a minimum (particularly by disposing of unused paint and packaging). A nano-enhanced coating only improves environmental performance when these three boundary conditions are fulfilled (which was the case for the coating containing nano- $\mathrm{TiO}_{2}$ ). Further studies could help to improve the environmental performance of new facade coatings, and exploiting this information should represent an opportunity for the industry.

Another result from our survey was the respondents' apparent general lack of knowledge about the disposal of ENP residues on objects contaminated during their production (i.e., containers, protective equipment, wipes, etc.), of tools used in their application (i.e., roller, sprays, and brushes), and of the nano-enhanced coatings on construction materials at the end of their useful life. Waste from ENP-based coatings is currently not regulated; however, there is a European waste catalog and a waste list for paints (which are considered hazardous), and consequently, their disposal could be monitored to some extent. Further research projects should be elaborated by the authorities in order to develop practical strategies and guidance on how to minimize the risks of handling these residues.

\section{Conclusions}

The semi-quantitative results of this survey reveal some short and long-term challenges that should be addressed by companies and the scientific community. One short-term challenge is the appropriate disposal of residues containing ENP-based coatings and of objects "contaminated" during their production and use (i.e., protective equipment). Large companies seem to dispose these residues as hazardous waste (according to EPA 2002). In contrast, SMEs and users do not have enough information about how to deal with residues containing ENPs. Here, the associations which represent producers of ENPs, ENP-based coatings (additives, resins) could provide advice to SMEs and users in collaboration with local authorities. Scientist should further analyze the fate of ENPs in the different disposal paths (incineration, landfill, water treatment facilities), e.g., (Caballero-Guzman et al. 2015; Müller et al. 2013). This knowledge will be very valuable also for the future disposal of large amount of building materials coated with ENP-based coatings.

Companies, especially SMEs, lack information on the type and physico-chemical properties of the ENPs that they integrate either directly or in the form of intermediates in their products. A proactive communication about the types of ENPs used among the actors along the value chain for nano-enhanced facade coatings may be beneficial for the efficient development of new coatings of high performance and safe handling of nano-enhanced facade coatings. Thus, the results of this survey should support more informed decision making in terms of the viability of integrating ENPs or nano-enhanced additives into coating formulations.

There are also medium and long-term challenges such as the not yet understood underlying mechanisms between the physico-chemical properties of ENPs and their interaction with the product matrix and the resulting functionality. Material scientist should provide more detailed information on the physical and chemical behavior of specific ENPs also in the context of the matrix material. Companies in collaboration with material scientists may develop a deeper understanding on how the physical and chemical structures influence the functionality of the coatings and thus, enable a more efficient design of ENP-based coatings.

The painting industry generally tends to go for water-based products and simpler formulations of paintings in order to provide coatings with a better environmental performance. Thus, companies and scientist should proactively exploit the potential for ENPs to improve environmental performance and could further develop a competitive edge for nanoenhanced facade coatings.

Acknowledgments We would like to acknowledge all the respondents from industry who participated in this survey and made this study possible. The research leading to these results received funding from the European Union Seventh Framework Program (FP7/2010-2013) under grant agreement $n^{\circ} 247^{\prime} 810$, 
"NanoHouse", as well as internal funds from Empa. We would also like to acknowledge the support of our project partners: CEA, Consorzio Venezia Ricerche, Katholieke Universiteit Leuven, Université Joseph Fourier (Laboratoire de Géophysique Interne et Tectonophysique), Materis Paints, GFC Chimica, Akzo Nobel Coatings, and PPG Industries.

\section{Compliance with Ethical Standards}

Conflict of interest The authors declare that they have no conflict of interest.

\section{References}

Al-Kattan A, Wichser A, Vonbank R, Brunner S, Ulrich A, Zuin S, and, Nowack B (2013) Release of TiO2 from paints containing pigment-TiO2 or nano-TiO2 by weathering. Environ Sci Process Impacts 15:2155-2358 doi:10.1039/ c3em00331k

Al-Kattan A, Wichser A, Zuin S, Arroyo Y, Golanski L, Ulrich A, Nowack B (2014) Behavior of TiO2 released from nanoTiO2-containing paint and comparison to pristine nanoTiO2. Environ Sci Technol 48:6710-6718. doi:10.1039/ c3em00331k

ANSES (2013) Éléments issus des déclarations des substances à l'état nanoparticulaire. French Agency for food, environmental and occupational health and safety, France

ANSES (2014) Éléments issus des déclarations des substances à l'état nanoparticulaire - exercice 2014. French Agency for food, environmental and occupational health and safety, France

Baer DR, Burrows PE, El-Azab AA (2003) Enhancing coating functionality using nanoscience and nanotechnology. Prog Org Coat 4:342-356. doi:10.1016/S0300-9440(03)001279

BCF (2013) Nanotechnology and the Coatings Industry, 8th October 2013. Write up. British Coatings Federation. http://www.coatings.org.uk/nanotechnology-seminar-2013write-up.aspx

Biswas P, Wu C-Y (2005) Nanoparticles and the Environment. J Air Waste Manag Assoc 55:708-746. doi:10.1080/ 10473289.2005.10464656

Caballero-Guzman A, Sun T, Nowack B (2015) Flows of engineered nanomaterials through the recycling process in Switzerland. Waste Manag 36:33-43. doi:10.1016/j. wasman.2014.11.006

EPA (2002) European Waste Catalogue and hazardous waste list

EPA (2007) Quantifying the disposal of post-consumer architectural paint. U.S. Environmental Protection Agency

Hamilton M (2009) Online survey response rates and times. Background and guidance for industry. Ipathia, Inc. Ipathia, Inc./SuperSurvey. http://www.supersurvey.com/ papers/supersurvey_white_paper_response_rates.htm

Hermann A, Küppers P, Möller M, Gross R (2009) Sichere Verwendung von Nanomaterialien in der Lack- und Farbenbranche - Ein Betriebsleitfaden. Hessisches Ministerium für Wirtschaft, Verkehr und Landesentwicklung, Wiesbaden
Hischier R, Nowack B, Gottschalk F, Hincapie I, Steinfeldt M, Som C (2015) Life Cycle Assessment of façade coating Systems containing manufactured nanomaterials. J Nanopart Res. doi:10.1007/s11051-015-2881-0

Jahnel J, Fleischer T, Seitz SB (2013) Risk assessment of nanomaterials and nanoproducts - adaptation of traditional approaches. J Phys: Conf Ser 429:1-11. doi:10.1088/17426596/429/1/012063

Kaegi R, Ulrich A, Sinnet B, Vonbank R, Wichser A, Zuleeg S, Simmler H, Brunner S, Vonmont H, Burkhardt M, Boller M (2008) Synthetic $\mathrm{TiO} 2$ nanoparticle emission from exterior facades into the aquatic environment. Environ Pollut 156:233-239. doi:10.1016/j.envpol.2008.08.004

Kaegi R, Sinnet B, Zuleeg S, Hagendorfer H, Mueller E, Vonbank R, Boller M, Burkhardt M (2010) Release of silver nanoparticles from outdoor facades. Environ Pollut 158:2900-2905. doi:10.1016/j.envpol.2010.06.009

Kaiser J-P, Zuin S, Wick P (2013) Is nanotechnology revolutionizing the paint and lacquer industry? A critical opinion. Sci Total Environ 442:282-289. doi:10.1016/j.scitotenv. 2012.10.009

Künniger T, Fischer A, Gerecke A, Heeb M, Kunz P, Ulrich A, Vonbank R (2010) Release of Conventional and NanoSized Biocides from Coated Wooden Façades during Weathering: Consequences for Functionality and Aquatic Environment. In: 53rd International Convention of Society of Wood Science and Technology, Geneva, Switzerland

Künniger T, Gerecke AC, Ulrich A, Huch A, Vonbank R, Heeb M, Wichser A, Haag R, Kunz P, Faller M (2014) Release and environmental impact of silver nanoparticles and conventional organic biocides from coated wooden façades. Environ Pollut 184:464-471. doi:10.1016/j. envpol.2013.09.030

Leydecker S (2008) Nanomaterials in architecture, Interior Architecture and design. Birkhauser Architecture, Berlin, pp 192

Lubick N (2009) Promising Green Nanomaterials. Environ Sci Technol 43:1247-1249. doi:10.1021/es900021v

Marolt T, Škapin AS, Bernard J, Živec P, Gaberšček M (2011) Photocatalytic activity of anatase-containing facade coatings. Surf Coat Technol 206:1355-1361. doi:10.1016/j. surfcoat.2011.08.053

Müller NC, Buha J, Wang J, Ulrich A, Nowack B (2013) Modeling the flows of engineered nanomaterials during waste handling. Environ Sci Process Impacts 15:251-259. doi:10.1039/c2em30761h

NanoHouse (2013) NanoHouse - Life cycle of nanoparticlebased façade coatings. European Comission. www.empa. ch/nanohouse, http://www-nanohouse.cea.fr

Penwarden R (2014) Response Rate Statistics for Online Surveys -What Numbers Should You be Aiming For? FluidSurveys University. http://fluidsurveys.com/university/ response-rate-statistics-online-surveys-aiming/. Accessed 8 Oct 2014

Piccino F, Gottschalk F, Seeger S, Nowack B (2012) Industrial production quantities and uses of ten engineered nanomaterials in Europe and the world. J Nanopart Res. 14:1109 doi:10.1007/s11051-012-1109-9

Plaschkies K, Jacobs K, Scheiding W, Schmid H (2010) Alternative Wirkstoffe für Holzschutzmittel. Holz-Zentralblatt $15: 376-377$ 
Rauscher H, Roebben G, Amenta V, Boix SA, Calzolai L, Emons H, Gaillard C, Gibson P, Linsinger T, Mech A, Quiros PL, Rasmussen K, Riego SJ, Sokull-Kluettgen B, Stamm H (2014) Towards a review of the EC Recommendation for a definition of the term " nanomaterial". Eur Union. doi: $10.2788 / 36237$

Saha S, Kocaefe D, Sarkar D, Boluk Y, Pichette A (2011) Effect of $\mathrm{TiO} 2$-containing nano-coatings on the color protection of heat-treated jack pine. J Coat Technol Res 8:183-190. doi:10.1007/s11998-010-9294-x

Saner M, Stoklosa A (2013) Societal and Administrative Benefits from the Analysis and Clarification of Definitions: the Case of Nanomaterials. Creat Innov Manag 22:26-36. doi:10.1111/caim.12014

Sangermano M, Malucelli G, Amerio E, Priola A, Billi E, Rizza G (2005) Photopolymerization of epoxy coatings containing silica nanoparticles. Prog Org Coat 54:134-138. doi:10.1016/j.porgcoat.2005.05.004

Som C, Wick P, Krug H, Nowack B (2011) Environmental and health effects of nanomaterials in nanotextiles and façade coatings. Environ Int 37:1131-1142. doi:10.1016/j.envint. 2011.02.013

Som C, Nowack B, Krug H, Wick P (2012) Towards the development of decision supporting tools that can be used for safe production and use of nanomaterials. Acc Chem Res 46:863-872. doi:10.1021/ar3000458

Som C, Zondervan-van den Beuken E, Van Harmelen T, Güttinger J, Bodmer M, Brouwer D, Buist HE, Carroll R, Coll
C, Fransman W, Hartmanis A, Hincapie I, Hischier R, Karachalios T, Kouravelou K, Kuijpers E, Ligthart T, Notter D, Nowack B, Seibold U, Schneider G (2014) LICARA Guidelines for the sustainable competitiveness of nanoproducts. Dübendorf, St. Gallen

UBA (2012) Concept for a european register of products containing nanomaterials. German Federal Environment Agency. http://www.umweltbundesamt.de/publikationen/ concept-for-a-european-register-of-products

Van Broekhuizen F, Van Broekhuizen P (2009) Nanoprodukte im europäischen Baugewerbe. Aktueller Sachstand 2009. Europäische Föderation der Bau- und Holzarbeiter/Verband der Europäischen Baugewerbe, Amsterdam

van Broekhuizen P, van Broekhuizen F, Cornelissen R, Reijnders L (2011) Use of nanomaterials in the European construction industry and some occupational health aspects thereof. J Nanopart Res Perspect 1-18 doi:10.1007/ s11051-010-0195-9

Zhou S, Wu L, Sun J, Shen W (2002) The change of the properties of acrylic-based polyurethane via addition of nanosilica. Prog Org Coat 45:33-42. doi:10.1016/S03009440(02)00085-1

Zuin S, Gaiani M, Ferrari A, Golanski L (2014) Leaching of nanoparticles from experimental water-borne paints under laboratory test conditions. J Nanopart Res 16:2185. doi:10. 1007/s11051-013-2185-1 